\title{
Conceptual Model of Technology-Enabled Creative Learning Community
}

\author{
Dawam Dwi Jatmiko Suwawi \\ School of Computing, Telkom University, Bandung, 40257, (+6222) 7564108 \\ e-mail: dawamdjs@telkomuniversity.ac.id
}

\begin{abstract}
This paper proposes a definition of Creative Learning Community (CLC) that is enabled with technology and its conceptual model in Graduate School of Telkom University. As rooted to learning community term, CLC is defined as a teaching and learning approach within a learning community that consists of a group of students and faculty member that uses creative learning concept. This study adapts the Design Science Research Framework in Information System by Hevner et al to build the conceptual model. First, the study synthesizes existing literature on learning community and creative learning community to define CLC term. Second, based on a review of previous studies and books on learning community, creative thinking, group creativity, engaged learning, student learning outcomes and technology supporting creative learning community, the author analyzes construct candidates of the model. Third, after selecting constructs from the candidates, the study continues by designing the conceptual model of technology-enabled creative learning community. The model was tested the implementations of learning community in Graduate School of Telkom University. The findings provide several conceptual and managerial insights into the role of technology in supporting creative learning community. Future work will need to evaluate the model in the context of other engineering.
\end{abstract}

Keywords - creative learning community, design science research framework in information system, technology as an enabler, creative thinking, learning community

\section{INTRODUCTION}

Learning communities have been studied since more than two last decades [1]. The study explores the implementation of learning communities to improve undergraduate education [2]. Besides, literature on learning community reveals that student participation in a learning community has positive link to students' engagement, outcomes and their satisfaction with college [3]. As Conejo et al. revealed that learning communities is endorsing the constructivism learning approach [4]; it is a paradigm that knowledge is constructed and transformed by students [5]. Therefore, it concluded that learning community is a learning strategy that boosts learner to build their own knowledge in such a group situation. This underlies several studies examining the correlation between students' engagement and the success achieved when they are involved in a learning community [3] [4]. The impact of the development of mobile and wireless technologies, the term of mobile learning community begins explored as a new topic research in learning communities [6]. It begins with the development of a new paradigm in electronic learning pedagogical design known as mobile learning [7] [8], ubiquitous e-learning [9] [10] [11], or just-in-time mobile learning [12]. The development of information and communication technology leads the education system to use computer, network or other technology devices as the learning tools in learning communities both in virtual [4] [13] [14] [15] or in actual environments [16]. 
In addition, high schools also use the concept of learning community that called as professional learning community (PLC) [17], [18]. This concept has been concerned since more than thirty years. It is used as "a strategy to increase students' achievement by creating a collaborative school culture focused on learning" [17]. In Indonesia, there is also a PLC-like which is called as community college (Perguruan Tinggi Komunitas), this is different from PLC because the program is a continuation of senior high schools, it is called as the post-secondary education. The program is proposed in order to build the national economy through the strengthening of regional economic (county and city). It is a higher education that takes $1-2$ years and the focus is on applied education. It is designed for a wider community for those who have been working or not, low-income workers, and the general public who require local technical skills (life skills) so that they are able to work and/or improve the quality of their practical skills [19].

Zhou's work [20] encouraged the development of creative skills in engineering program within group situation, particularly through problem and project-based learning approach. Because creativity is the vital characteristic needed to create innovation in engineering programs, Psychology and Engineering Program of Ohio University developed Creative Engineering Design Assessment (CEDA) [21] [22]. Creative personality, cognitive risk tolerance, and engineering creativity are the CEDA scores that characterize the students between genders (men and women).

The study about group creativity was popularized by Goran Ekval in 1983 encouraged many researchers to examine the creative climate within a group or organization, Creative Climate Questionnaire (CCQ) was an instrument he developed "to assess how much any particular context will support creativity and change" for organizational diagnosis and development [23]. Decades before, the studies about creative thinking emerged. Bacanlı et al, describe creative thinking with quadruple thinking which consists of "critical thinking, creative thinking, caring thinking and hopeful thinking ways" [24].

They added three Mathew Lipman's teaching thinking consisting of "critical thinking, creative thinking, and caring thinking" with "hopeful thinking" as "in consideration of the needs of Turkish society" [24]. They divided teaching thinking ways into two dimensions through with "cognitive-affective and "convergent-divergent" [24]. Edward de Bono as one of the central figures in this area, then originated the lateral thinking term [25]. Lateral thinking is regarding with insight, creativity, and humor [26].

The use of technology to support learning process collaboratively is widely known as technology-supported collaborative learning [27]. It's known that the use of technology in supporting learning process designed by colleges or universities has some purposes. As revealed by Resta and Laferrière, the purposes of colleges or universities provide learning process with supporting technology is "to prepare students for the knowledge society, to enhance student cognitive performance or foster deep understanding, to add flexibility of time and space for cooperative/collaborative learning, to foster student engagement and keep track of student cooperative/collaborative work (online written discourse)" [9]. Collaborative learning is a concept that "emphasizes providing a shared workplace for students to interact and learn through cooperation" [9]. It focuses on "students" exploration or application of the course material, not simply the teacher's presentation or explanation of it" [28].

A framework for collaborative systems assessment has been studied by Cugini et al [29]. It describes the "collaborative capabilities, that is: human communication, persistent shared object manipulation, archival of collaborative activity and so forth" [30]"The main quality characteristics of the collaborative systems" as cited by [30] in [29] namely, "correctness, flexibility, interoperability, maintainability, reliability, testability, and consistency". Damianos, et al propose Evaluation Working Group (EWG) Framework for Collaborative Systems "to facilitate description of a collaborative system and to evaluate how well that system supports various kinds of collaborative work" [29]. It has four levels: requirement, capability, service, and technology. There is also a model to measure information 
system success known as DeLone and McLean (D\&M) model using the six dimensions: system quality, information quality, service quality, use, user satisfaction, and net benefits [31].

To propose a model which integrates the creative learning in learning community at the Graduate School of Telkom University, this study began with deepening the understanding of learning community and creative learning community concept. The process of understanding of creative learning community concept was meant to select the course/s that was/were relevant with the concept/characteristics. After selecting the course, the study continued to observe the learning process characteristics of the selected course by using adapted Situational Outlook Questionnaire (SOQ). In this process, the characteristics of learning community in EGS were found with mixed quantitative and qualitative approaches. Subsequently, the study was continued by designing the model. The model design process begins with analyzing related construct candidates to the characteristics of learning community found in literature. This process produced eight construct candidates that later will be set as the construct of the model.

Then, the study was moving forwady by taking considerations to eliminate some construct candidates. The model design process ending with grouping the rest of construct candidates into two parts; these two parts of constructs were used to build the conceptual model. Besides, the model was equipped with methods of application of the model. It was evaluated using expert judgment that involved some informants as the expert. Finally, some recommendations were made to propose the implementation of Creative Learning Community concept that using technology as enabler to the environment. All of the processes of designing the conceptual model were following the framework of Hevner et al [32]. The following discussed the framework in more details.

\section{RESEARCH METHOD}

The research is intended to build the basic design of the creative learning community model and the construct candidates of the model. The research framework used in this thesis was adapting the Information System Research Framework by Hevner, et al., as shown in Figure 1. The development of conceptual model of creative learning community was conducted through three phases, which is, learning community characteristics determination, constructs analysis, and design. The model of the creative learning community was evaluated with exploratory single case study approach at Master Program in Informatics Engineering of Graduate School of Telkom University. 


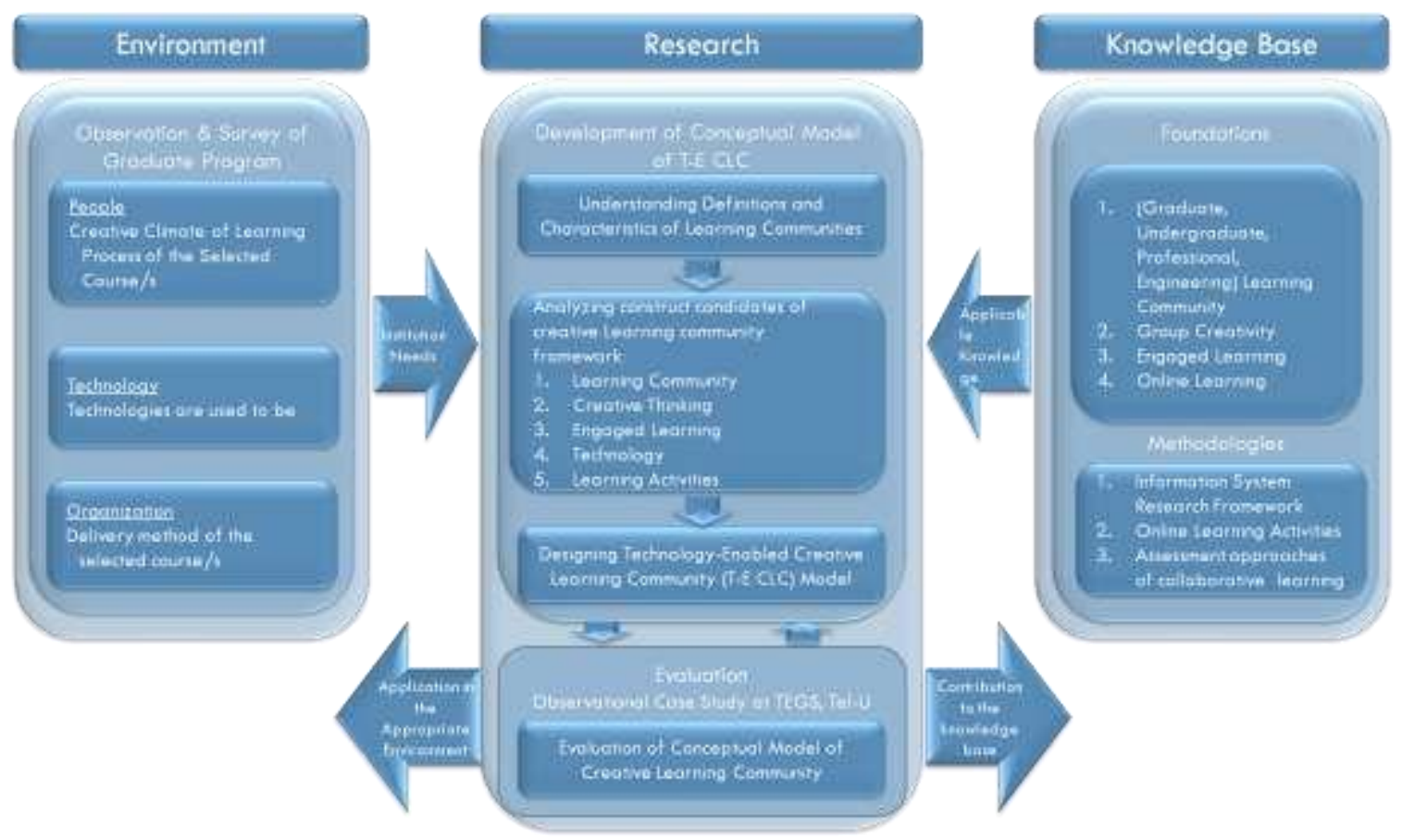

Fig. 1 Research methodology adapted from IS research framework of Hevner et al., [32]

Deriving from the research methodology in Fig. 1, the development schema of the conceptual model was aimed to build Creative Learning Community Model. Generally, the model was conducted through three phases, which is:

1. Understanding Definitions and Characteristics of Creative Learning Communities

2. In this first phase, there are three steps. First, define the term of learning community generally. Second, define the characteristics of learning community. Third, define the term of creative learning community which is meant in this thesis. This phase was intended to comprehend the understanding of creative learning community used as basic concept in the model proposed.

3. Analyzing construct candidates of creative Learning community, and learning community development framework and

4. Designing the conceptual model of technology-enabled creative learning community based on learning community characteristics, construct determination, and constructs interaction and technology analysis. This third phase has already discussed and published in [33]. Due to limitations of the page

The environment defines the domain space of the research. It was composed of Learning Characteristics of students, the role of faculty and capability of the program to support learning process (people), technologies supporting the learning process (technology), and the Program of Graduate School Telkom University (organization). The goals, tasks, problems, and opportunities of the environment defined business needs which were recognized by people within the organization. As Hevner, et al., explained in their paper "the business needs are assessed and evaluated within the context of organizational strategies, structure, culture, and existing business process. They are positioned relative to existing technology infrastructure, applications, communication architectures, and development capabilities." [32].

This research combines the design science and behavioral science research, because it needs to analyze the behavioral aspects of the environment and as a contribution it will produce 
a model which is a design product. As behavioral science conducted, the research begins with survey of current learning process in Graduate School of Telkom University. Then, as design science research conducted, from the problem or business need surveyed, the research is accomplished through the design building and evaluation. Cited the work of Hevner, et al., "research assessment via justify/evaluate activities can result in the identification of weaknesses in the theory or artifact and the need to refine and reassess. The refinement and reassessment process is typically described in future research directions." [32].

The knowledge base gives the "raw materials" this research comes from and will be accomplished through. The foundations are resulted from prior researches and literatures related to this research topic. The foundations that emerge until now are graduate learning community, professional learning community, group creativity, and creative climate.

\section{PROPOSING THE CONCEPTUAL MODEL}

\section{A. Phase 1: Understanding Definitions and Characteristics of Learning Communities and Creative Learning Communities}

This study was inspired by the way of Adhy [34] to describe his analysis process, a brief explanation about purpose, object, method, and output of this analysis phase is shown in Table 1.

Table 1 Understanding definitions and characteristics of learning communities Understanding Definitions and Characteristics of Learning Communities

\begin{tabular}{|l|l|}
\hline \multicolumn{2}{|c|}{ Understanding Definitions and Characteristics of Learning Communities } \\
\hline Purpose & Defining the term of learning community and its characteristics (generally) \\
\hline Object & Definitions of learning communities, Characteristics of learning communities \\
\hline Method & $\begin{array}{l}\text { Summarize the definitions and characteristics of learning community that were } \\
\text { found in literature }\end{array}$ \\
\hline Output & Definition of learning community and its characteristics \\
\hline
\end{tabular}

The definitions and characteristics of learning community and creative learning community are discussed in subsequent subchapters.

1). Defining Learning Community

In defining the term of learning community, this subchapter summarized learning community definitions reviewed from literatures. The summary of learning community definitions were presented in Table

Table 2 Summary of learning community definitions from literatures

\begin{tabular}{|l|l|}
\hline \multicolumn{1}{|c|}{ Sources } & \multicolumn{1}{c|}{ Definition of Learning Community } \\
\hline Kraska [35, p. 55] & $\begin{array}{l}\text { "A group of participants who enter a program together and enroll in } \\
\text { most courses together" }\end{array}$ \\
\hline $\begin{array}{l}\text { Norris and Barnett } \\
\text { (1994) in [35, p. 55] }\end{array}$ & $\begin{array}{l}\text { Purposely formed and structured groups to create an environment for } \\
\text { effective learning }\end{array}$ \\
\hline $\begin{array}{l}\text { Rasmussen and } \\
\text { Skinner (1999) in [35, } \\
\text { p. 56] }\end{array}$ & $\begin{array}{l}\text { "Specially designed curricula in which two or more courses in a single } \\
\text { program are coordinated" }\end{array}$ \\
\hline $\begin{array}{l}\text { Cross (1998) in [35, p. } \\
\text { 56] }\end{array}$ & $\begin{array}{l}\text { "A cohort of students who take one or more courses together where the } \\
\text { courses are linked together through a } \\
\text { common theme" }\end{array}$ \\
\hline $\begin{array}{l}\text { Gabelnick in [2, p. } \\
\text { 179] }\end{array}$ & $\begin{array}{l}\text { "The purposeful restructuring of the curriculum by linking courses that } \\
\text { enroll a common cohort of students. This represents an intentional } \\
\text { structuring of the students' time, credit, and learning experiences to } \\
\text { build community, and foster more explicit connections among students, }\end{array}$ \\
\hline
\end{tabular}




\begin{tabular}{|c|c|}
\hline & faculty, and disciplines" \\
\hline $\begin{array}{l}\text { Lawrence in }[35, \mathrm{p} . \\
56]\end{array}$ & $\begin{array}{l}\text { "Students and teachers engaged in a process of mutual inquiry and } \\
\text { reflection through the sharing of ideas, experiences, and perspectives" }\end{array}$ \\
\hline Lenning \& Ebbers [1] & $\begin{array}{l}\text { "A community developed intentionally that will promote and maximize } \\
\text { learning" }\end{array}$ \\
\hline $\begin{array}{l}\text { Brower \& } \\
\text { Dettiner in [3, p. 116] }\end{array}$ & $\begin{array}{l}\text { "Learning community have some common academic and social } \\
\text { features, such as the same groups of students taking two or more classes } \\
\text { together" }\end{array}$ \\
\hline Conejo et al. [4, p. 905] & $\begin{array}{l}\text { "Learning community (LC) is widely used as an instructional resource } \\
\text { to promote the constructivism learning approach" }\end{array}$ \\
\hline $\begin{array}{l}\text { Conrad \& } \\
\text { Donaldson [36, p. 2] }\end{array}$ & "...humans do not learn in a vacuum but rather through interaction." \\
\hline
\end{tabular}

Based on those definitions found in literature, learning community which is meant by this paper is as follows:

Learning community is "an intentional restructuring of the curriculum by linking one or more courses that enroll a group of students and fostering explicit connections among students and faculty members through sharing ideas, experiences, and perspectives which will build their own knowledge or understanding" [37].

To describe about what, why, how, as well as goal of the learning community Table 3 describes it in more detail.

Table 3 Definition of learning community

\begin{tabular}{|l|l|}
\hline \multicolumn{2}{|c|}{ Definition of Learning Community } \\
\hline What? & Learning approach within a group situation \\
\hline Why? & Students learn more through interaction with other students and faculty members \\
\hline How? & $\begin{array}{l}\text { Intentionally restructuring of the curriculum by linking one or more courses that enroll a } \\
\text { group of students through sharing ideas, experiences, and perspectives to foster } \\
\text { constructivism learning approach }\end{array}$ \\
\hline Goal & $\begin{array}{l}\text { To foster connections among students and faculty members which will maximize } \\
\text { learning and } \\
\text { build students' own knowledge or understanding }\end{array}$ \\
\hline
\end{tabular}

2). Defining Characteristics of Learning Community

To define the characteristics of learning community (LC) this paper digs literatures that are taken from a wide variety of LC such as LC in postsecondary education [37], LC in undergraduate school [1], professional LC in nursery, primary, secondary and special schools in England [38], LC in graduate school [39], [35], and faculty learning community in higher education (graduate and undergraduate degree) [40].

To summarize those characteristics of LC, this paper just combine those characteristics into statements that cover the whole meaning of each characteristics from the literature. The summarized characteristics of an LC are shown in Table 4.

Table 4 Summary of learning community characteristics

\begin{tabular}{|l|c|c|c|c|c|c|c|}
\hline \multicolumn{1}{|c|}{ Characteristics of Learning Community } & A & B & C & D & E & F & G \\
\hline Sharing values, vision and culture about learning or & & & & & x & x & x \\
\hline Collaborative and participation in learning & x & x & x & x & x & & x \\
\hline Integrated curriculum & & x & x & x & & & \\
\hline Students and faculty interaction in a group & & x & x & x & & & \\
\hline
\end{tabular}




\begin{tabular}{|l|l|l|l|l|l|l|l|l|}
\hline Establishing links and partnership & & & & $\mathrm{x}$ & $\mathrm{x}$ & $\mathrm{x}$ & \\
\hline Student outcomes inquiry, assessment and & & $\mathrm{x}$ & $\mathrm{x}$ & $\mathrm{x}$ & $\mathrm{x}$ & & \\
\hline Promoting trust, support, respect caring, and support & & & & & $\mathrm{x}$ & $\mathrm{x}$ & \\
\hline Consistent with mission of the institution & & & $\mathrm{x}$ & $\mathrm{x}$ & & & \\
\hline
\end{tabular}

A: (Lamb, Kabes, Engstrom, 2012); B: (Taylor, Moore, MacGregor, \& Lindblad, 2003); C: (Kraska, 2008); D: (Price, 2005); E: (Bolam, McMahon, Stoll, Thomas, \& Wallace, 2005); F: (Lenning \& Ebbers, 1999); G: (Cox, 2004); H: (Khoo \& Cowie, 2011)

In conclusion, the characteristics of learning community based on those claims are shown in Table 5.

Table 5 Summary of learning community characteristics

\section{Characteristics of Learning Community}

1 Sharing values, vision, culture about learning or leadership [1] [38]

2 Collaboration and participation of students, faculty in the learning community program [40] [37] [38] [35] [39]

3 Integration of the curriculum [41] [40] [35]

4 Organizing faculty and students into groups [41] [37] [35]

5 Establishing academic and social networks/links and partnership [1] [37] [38]

6 Inquiry, assessments and communications of student outcomes [1] [41] [37] [38] [6] [35]

7 Consistency of learning community programs with the mission, expectations, structure, processes, culture, and climate of the institution [41] [37] [35]

8 Promoting caring, trust, respect, teamwork, and support [1] [38]

3). Defining Creative Learning Community

After defining the term of learning community and its characteristics, the term of creative learning community (CLC) is need also to be defined clearly here. Definitions or explanations of creative learning community found in literature are shown in Table 6.

Table 6 Summary of creative learning community discussion

Sources $\quad$ Term of Creative Learning Community

Mastergeorge Combination of creative thinking, problem solving and constructivism

et al., [42, p. 1] paradigm; it consists of creative teaching strategies to foster positive change in school reform that is considered necessary to enhance student learning

Beal et al., [43] New teaching and learning tools are best developed via a process of engaged, enlightened and inclusive co-creation; individuals not only collaborate together to generate ideas, but also to tackle common problems and, most importantly, to learn from each other's experiences through the use of creative thinking

There are just two literatures that can be found, up to now, in this context. It indicates that the study of creative learning community is still at the beginning. The literatures are dissimilar in the intended context of "community" [33]. The first one is in the school level, including learner and teacher communities; whether the second one is in Vocational Education and Training (VET) training organizations, including VET learner and VET trainer communities.

From those two literatures creative learning community defined in this paper is referred to definition of previous paper, that is:

"A teaching and learning approach within a learning community that consists of a group of students and faculty member that uses creative learning concept which comprises creative thinking and engaged learning paradigm through a set of learning activities including generating ideas, solving common problems, and learning from each other's experiences, ideas or perspectives to enhance student learning" [37]. 
To comprehend the understanding about creative learning community, detail descriptions about what, why, how as well as goal of the creative learning community are shown in Table 7.

Table 7 Definition of creative learning community

\begin{tabular}{|c|l|}
\hline \multicolumn{2}{|c|}{ Definition of Creative Learning Community } \\
\hline What? & $\begin{array}{l}\text { Teaching and learning approach within a group situation that use creative thinking } \\
\text { paradigm }\end{array}$ \\
\hline Why? & $\begin{array}{l}\text { Creativity is a skill needed to address challenges of future engineering students' } \\
\text { workplaces in globalization era; students ideas need to be generated to become } \\
\text { creative }\end{array}$ \\
\hline How? & $\begin{array}{l}\text { Through collaboration between students and faculty members by idea generation, } \\
\text { mutual problem solving, and sharing learning experience from others }\end{array}$ \\
\hline Goal? & To foster creative teaching strategies that are needed to improve student learning \\
\hline 4$). \quad$ Defining Characteristics of Creative Learning Community
\end{tabular}

Since the references discussing the characteristics of Creative Learning Community (CLC) are very limited, the process to define the characteristics of CLC in this chapter focuses on the two literatures by Mastergeorge et al. [42, p. 7] and Beal et al [43].

The first literature by Mastergeorge, et al., did not discuss explicitly about characteristics of of the intended creative learning community. They just declared that they adopted creative teaching strategies, such as "teaching practices that foster exploration and indepth understanding, classroom environments that support student risk-taking, inquiry, and imagination, and assessment practices aligned with creative learning" [42, p. 6]. By their theory of action, they proposed five major domains that are needed to establish learning communities, which are shown in Table 8.

Table 8 Theory of action by Mastergeorge et al. [42, p. 7]

\begin{tabular}{|c|c|c|}
\hline \multirow{7}{*}{$\frac{\text { Domains }}{\text { Embed in school culture }}$} & \multicolumn{2}{|r|}{ Actions } \\
\hline & 1. & Mobilize change \\
\hline & 2. & Facilitate change \\
\hline & 3. & Attend to cultural and structural change \\
\hline & 4. & Anchor in curriculum, instruction, and assessment \\
\hline & 5. & Connect to student learning \\
\hline & 6. & Build a shared vision \\
\hline \multirow{6}{*}{$\begin{array}{l}\text { School Culture and } \\
\text { Structure [environment] }\end{array}$} & 7. & Embed in school culture \\
\hline & 8. & Build a community \\
\hline & 9. & Attend to changing attitudes, beliefs, and values \\
\hline & 10. & Provide materials \\
\hline & 11. & Provide financial support \\
\hline & 12. & Provide technical support \\
\hline \multirow{6}{*}{$\begin{array}{l}\text { Professional } \\
\text { Development and } \\
\text { Accountability }\end{array}$} & 13. & Embed in classroom practice \\
\hline & 14. & Provide opportunities for teacher collaboration \\
\hline & 15. & Promote and provide time for ongoing professional inquiry \\
\hline & 16. & Align with project goals \\
\hline & 17. & $\begin{array}{l}\text { Provide the type of and timely information for project } \\
\text { adjustments }\end{array}$ \\
\hline & 18. & Develop measures aligned with creative teaching practices \\
\hline \multirow{5}{*}{$\begin{array}{l}\text { Creative Teaching } \\
\text { Practices }\end{array}$} & 19. & Identify innovative practices \\
\hline & 20. & Shift teacher attitudes, beliefs, and expectations \\
\hline & 21. & Align with standards \\
\hline & 22. & Link to curriculum \\
\hline & 23. & Align with assessments (standardized and performance) \\
\hline
\end{tabular}




\begin{tabular}{|l|c|l|}
\hline \multicolumn{2}{|c|}{ Domains } & \multicolumn{2}{|c|}{ Actions } \\
\hline \multirow{3}{*}{$\begin{array}{l}\text { Engaged Student } \\
\text { Learning }\end{array}$} & 24. & Embed in school culture \\
\cline { 2 - 3 } & 25. & $\begin{array}{l}\text { Promote the "joy of learning" through exploration, } \\
\text { collaboration, and interpretation }\end{array}$ \\
\cline { 2 - 3 } & 26. & $\begin{array}{l}\text { Promote basic skills in the context of complex thinking } \\
\text { and problem solving }\end{array}$ \\
\cline { 2 - 3 } & 27. & Improve student achievement on multiple measures \\
\cline { 2 - 3 } & 28. & Improve students attitudes towards learning \\
\hline
\end{tabular}

Similar to the first reference, the second reference also did not mention clearly what are the characteristics of the CLC they intend. They just mention the corresponding concepts and competences needed to establish (CLC) as their standard to run the project. So, by synthesizing the description of definition and concept of the (CLC) in their official website, Table 9 describes the knowledge, skills and attitudes that are summarized from the official website of Creative Learning Communities Project ${ }^{1}$.

Table 9 Corresponding knowledge, skills and attitudes as well as each competences to establish CLC [43]

\begin{tabular}{|l|l|l|}
\hline CLC Concepts & \multicolumn{2}{|c|}{ Competences } \\
\hline Knowledge & 1 & The ability to identify available opportunities for personal activities, \\
professional activities, business activities
\end{tabular}

From the above discussion, the characteristics of (CLC) in this paper is derived from the previous characteristics of learning community combined with creative teaching strategies and engaged student learning domain of the first literature and skills and attitudes concept of the second literature:

Table 10 Characteristics of CLC found in literature

\begin{tabular}{|ll|}
\hline \multicolumn{1}{|c|}{ Characteristics of CLC } \\
\hline 1. & Using innovative practices in teaching [42] \\
\hline 2. & Influence students with attitudes, beliefs and CLC expectations [43] \\
\hline 3. & Align with standards, mission, structure, culture and climate of the institution [41] [37] [35] \\
\hline
\end{tabular}

${ }^{1}$ See http://www.skills4me.eu/index.php/en/home-uk/project/clc-concept-and-definitions 


\begin{tabular}{|c|}
\hline Characteristics of CLC \\
\hline 4. Link or integration to curriculum [41] [37] [35] \\
\hline 5. Organizing faculty members and students into groups [41] [37] [35] \\
\hline 6. Promote the "joy of learning" through exploration, collaboration, and interpretation [43] \\
\hline 7. Promote basic skills in the context of complex thinking and problem solving [44] \\
\hline 8. Improve and align student achievement on multiple measures [1] [41] [37] [38] [35] \\
\hline $\begin{array}{l}\text { 9. Plan, organize, manage, lead and delegate, analyze, communicate, de-brief, evaluate and } \\
\text { record effective presentation [43] }\end{array}$ \\
\hline 10. Working as individual and collaborative teams [43] \\
\hline 11. Identifying personal strengths and weaknesses [43] \\
\hline 12. Proactive and positive response to change [43] \\
\hline 13. Assessing and taking risks when warranted [41] \\
\hline
\end{tabular}

The comparison between the characteristics of learning community and CLC shows that the CLC is an advanced level of learning community. The main difference is the emphasis on learning. CLC emphasizes the learning process in the development of thinking skills of the students to be creative in solving problems encountered, and of course, as a community problem solving is done by utilizing existing resources in the community. As a community member who has diverse backgrounds, the facilitator in the CLC are required to deliver a series of learning activities that can connect a variety of backgrounds so that the input received by each student will be more varied and at the end they have a variety of ways with the input to solve the problems they face in the future.

Deriving from the characteristics of CLC mentioned in Table 10, Table 11 describes the characteristics of course/s that is/are appropriate to apply CLC concept.

Table 11 Characteristics of course applying CLC concept Characteristics of course/s applying CLC concept

1. Implementation of the course is divided into groups of students

2. The effectiveness of the implementation of the course have a dependence with the magnitude of the initiatives taken by every member of the community

3. The successful achievement of the students in the course depends on the level of creativity and engagement in participating in lecturing process by expressing ideas, opinions, or updates on topics about the course and respond them proactively

4. There is flexible learning activities of the course designed by considering the background of the student and the learning objectives to be achieved

5. There is a complex problem that is discussed in the learning process of the course and the completion of the course requires the sharing of experiences, ideas, and perspectives of community members

6. There is a learning environment of the course that supports student risk-taking, inquiry, and imagination

7. There is an assessment of the course that is aligned with CLC process

B. Phase 2: Analyzing Construct Candidates of Creative Learning Community Framework and Designing the Conceptual Model

A brief explanation about purpose, object, method, and output of this analysis phase is shown Table II .12-

To focus the discussion on this topic, the following are scope of the creative learning community (CLC) intended in this paper:

1. CLC is an approach for teaching and learning within a group of students that is facilitated by a faculty member.

2. CLC is implemented through creative thinking by idea generation; mutual problem solving; sharing experience of learning from others; and enabled by initiative and technology. 
3. The understanding of knowledge is built by students' own effort through constructivism approach used by the facilitator.

4. Constructivism and creative thinking on a learning community is implemented by applying some of the principles in the form of learning activities

Table 12 Analyzing construct candidates of CLC framework

\begin{tabular}{|l|l|}
\hline \multicolumn{2}{|c|}{ Analyzing Construct Candidates of CLC Framework } \\
\hline Purpose & $\begin{array}{l}\text { Analyzing the knowledge base which is based on concepts and previous } \\
\text { researches about development of CLC as well as interaction between them }\end{array}$ \\
\hline Object & 1. Learning Community \\
& 2. Creative Thinking \\
& 3. Group Creativity \\
& 5. Engaged Learning \\
\hline Method & $\begin{array}{l}\text { Analyzing the charning } \\
\text { candidates and explaining their interactions }\end{array}$ \\
\hline Output & Construct candidates of CLC and interaction between them \\
\hline
\end{tabular}

From the scope of CLC, it can be determined that a CLC has four components, that is: group of students, creative thinking, constructivism and learning community framework.

\section{1). Learning Community}

A creative learning community (CLC) is run within a group situation that applies creative thinking approach paradigm. The group member of a learning community intended in this paper was a group of students or also called as student learning community. The result of student learning community mentioned by Stark \& Lattuca in Lenning \& Ebbers increases student involvement in learning and student motivation in higher levels. Those are because students learn from each other's experiences, ideas, or perspectives including from participating faculty. Even though faculty organize them, generally, but the students are the predominant participants [1, p. 15].

"The membership, format, linkages and programming of a student learning community are purposefully designed to facilitate the maximum amount, mastery, effectiveness and efficiency of learning" said Lenning \& Ebbers. The students can interact to learn both inside and outside the classroom; besides they also can interact via other modes of communication such as e-mail, internet (chatting) or interactive video (in nowadays trend such as Skype, Google Hangout, etc.) [1, p. 16].

The student involvement and motivation are intrinsic factors of students that are supported in group situation. So the learning outcomes such as mastery, effectiveness and efficiency of learning can be facilitated through it.

\section{2). Initiative}

As discussed previously initiative was becoming one of attitudes that characterize a creative person. According to thefreedeictionary.com, initiative is defined as "A beginning or introductory step; an opening move" 2 . Beside, consistent with oxforddictionaries.com, initiative is defined as "the ability to assess and initiate things independently" 3.

According to Beal et al., [43], initiative is one of attitudes that also characterize a learning community regarded as a CLC, beside proactivity, innovative and independent. While in the world of sales, Iannarino, the president and chief sales of a manpower supply company, said that, "initiative is the ability to take action proactively" [45]. It shows that there is a connection between initiative and other attitudes of creative learning community.

In the industrial world, initiative is a good trait that most employers look for from their employees. Similar with students and faculties in college, students are asked for taking initiatives in their own learning process. When they are connected to the creative process, 
initiative is required in terms of expressing ideas, solve problems, learn from the others' experience, and risk taking.

When students express an idea, they should have the initiative to determine what ideas and how to express the idea that they were thinking of to learning community members, so discussion took place, then a brainstorming or exchange ideas submitted in response to each of the members, taking risk for their own and so on.

Similarly, in problem solving, initiative is needed to solve the problems faced by the group. For example, when a student discovered a problem when doing group assignments which they are responsible, they must take the initiative whether the problem he faces require discussion by the whole learning community members or the problem can be solved by him/herself.

Likewise with the process of learning from the others' experience in the learning community, each student is required to take a lesson from that experience which is becoming an initiative of him whether he will use this experience as a reference action in the future or he will try another solution beside the lesson learnt from the experience.

Initiative is also related to engagement. Iannarino said in his web blog, "initiative means being fully engaged in what you are doing and being thoughtful enough to decide what can be done to achieve a positive outcome on your own" [45]. So, in a learning community, especially in creative learning community, initiative is one of the main elements that contribute to success learning community.

This thesis defines initiative as the ability to express ideas, solve problems, learn from the others' experiences, and take risks to sustain creative learning community proactively.

\section{3). Creative Learning}

As previously mentioned in definition of creative learning community, creative learning as a construct candidate consists of three components, namely: creative thinking, engaged learning and learning activities.

a) Creative thinking

As revealed by Zhou, Engineers require creative solutions in addressing urgent global issues in their future workplaces. The creative thinking is believed not just an accessory for engineering works but it has become a necessity for engineers. This because the diverse of engineering fields that has highly interactions between its components in engineering practice, such as science, technology, economic, human and sociology, etc; and the large number of issues that they have to consider, such as technical function, economic feasibility, safety requirements, ethical issues, resources considerations, etc.; and also in c complex knowledge that causes an ambiguity and uncertainty.

Because of that, the implementation of creative thinking in students' learning process is becoming a need to prepare, especially for engineering students, facing challenges in their future workplaces. They need to get used to thinking creatively. As activity in formal education in general, creative learning at the college requires proper design and strategies that can be measured how much of the increase in learning ability of students when they learn creatively.

To design creative learning in higher education, some of the characteristics in creative learning that need to be considered according to the literature, e.g. new idea generation, communicate effectively, learning collaboratively, shared learning experiences from others, problem solving creatively, and capability to take a risk.

Generating new ideas combine divergent and convergent thinking. Divergent thinking reviews ideas and solutions in a maximum openness which, in practice, avoids judgments of something in early stage of exploration. By opening mind to think, the process to generate ideas is continued by convergent thinking. This process finds the most suitable solution with knowledge, analysis and judgment already owned by students.

Effective communication skill is a key to share ideas to get feedback from others. Because students learn in a group situation, they also need to learn collaboratively with peers. And, of course, as creative students, they are also required to be able to learn from their or the 
other's experiences, ideas, or perspectives. In case, students propose some new ideas, they also need to be encouraged to take risks when proposing or implementing the ideas. Those sorts of skills are needed to solve problems creatively.

b) Group Creativity

Like the proverb saying that good fruit comes from a good tree. Strong roots and branches of towering into the sky illustrate strong foundation of the tree. Likewise learning, creative ideas generated from creative learning environment as well.

Creative learning environment can be seen from the learning climate. Creative learning climate has certain characteristics that can be observed from the interaction between members of the learning community. Characteristic or dimension of group creativity by Goran Ekvall is the basis of this study.

Commitment of members of the learning community to achieve learning objectives and the level of emotional involvement of each member in the learning environment is one of the characteristics of creative learning environment. The greater involvement of community members in the interaction, the greater the sense of community exist in the learning process. And togetherness in this study provides an excellent stimulus for the creation of a creative idea.

Discretion in learning also has a positive influence on learning outcomes, especially learning outcomes which are creative. Initiative in acquiring the information and determining the choice or decision is a hallmark of a creative learning environment.

Creative environment requires openness in the relationship between members of the learning community. This openness provides a safe atmosphere thereby increasing confidence among members of learning community. And when confidence is growing in the learning environment, then this setting can provide opportunities for the generation of new/creative ideas.

Creative ideas do not emerge offhand; it takes a considerable time to produce new ideas from existing previous ideas. Creative ideas in the academic world are needed to develop science and knowledge. As the proverb says, "stand on the shoulders of giants". It means a new discovery is found from the discoveries that have been there before.

One indicator of openness that exists in learning is the jokes/laughter positive. Positive jokes or laughter indicates that there is an excitement on every member of the learning community. Positively, the joy gives a feeling of happiness that is conducive to generating creative ideas from members of the learning community.

Sometimes to generate creative ideas, there is positive conflict or debates happen among members of learning community. The debate here is certainly not a sophist whose aim is not to find the truth or just to show the influence of someone or individual ego in the group. The debate that addressed wisely will produce real truth. And this truth will generate creative ideas.

Positive attitude in response to the ideas presented by the peer of learning community is another characteristic. The positive attitude is like give responses or feedback wisely and keep upholding the values of honesty or truth contained in the idea. It is important to develop a conducive environment to the creation of creative ideas for the group of learning community.

And one of the other characteristics of learning environment that generates creative ideas is the courage of members of the group on the learning environment to take risks against the idea that he had to say.

c) Engaged learning

Engaged learning is a situation that occurs through interaction among students and also interaction between students and faculty that applies constructivism and problems-based learning within a collaborative environment.

In the context of learning, it is believed that the construction of students' own knowledge is the best way of learning. It is widely acknowledged as constructivism. This paradigm of thinking values social interaction in the learning process.

The thesis agreed the concept of engaged learning by Conrad \& Donaldson who revealed that active participation of learners in learning situation is the result of an engaged learning. Engaged learning is occur through constructivism and problem-based learning within a 
collaborative context. In addition, to conduct the creative learning community there will be a set of learning activities that has to be designed before.

d) Learning activities

As previous chapter' discussion, to result a successful implementation of creative learning community, the main focus is to plan and design it in a set of activities. As Conrad \& Donaldson revealed that the development of engaged learning is not simply happen. There is, as they call, "architectural engineering" that need to be considered before. The planning and utilizing activities that assist learners in going through the developmental phases of engaged learning make sure that they are motivated and capable of interacting and collaborating successfully in an online learning environment and, in the end, they engage in independent knowledge building.

There is a need of purposeful design of learning activities in constructivist learning. Learning activities meant are activities of learning that stimulate students to construct their own knowledge. The activities will connect current students' knowledge with something they want to learn. The activities will never let lectures to lecture, but rather coach the students in achieving learning objectives. This coaching approach encourages lecturers to use technology in delivering learning materials.

The capability of technology in affording interactive communication through email, bulletin boards, chats or web-based conferencing enhance the quality of students' learning.

\section{4). Technology in Creative Learning Community}

Technology utilization is becoming current trend as a tool for learning collaboratively with colleagues, especially in higher education. Services such as remote desktop sharing, workflow management, collaborative project management, over-the-top mobile application, shared calendar, online memo bureaucracy application or even an augmented human conferencing are examples of those tools used nowadays. Those tools encompass synchronous and asynchronous collaboration; in collocated or remote place.

In higher education, those tools challenge the role of lecturer as educator. As mentioned by Aamarin \& Ghishan in their 2013 paper, “...collaborative technologies reflect current trends for collaborative student work and challenge our roles as educators. Collaborative learning can be computer-mediated the latter being the most favored" [46, p. 53].

Technology as an enabler in supporting learning activities within a creative learning community (CLC) has a meaning that technology enables learning activities in the CLC happen. Learning activities in CLC has its own characteristics that distinguish it from the learning activity in the learning situation regularly.

The work of Schmid (2006) in Amarin \& Ghishan [46, p. 53] reveals characteristics of technology use in learning inspired the understanding about the role of technology as an enabler of CLC. Students' understanding of a subject affected by many factors, the most influential one is about how the course delivered to them by the lecturer. Methods of course materials delivery by lecturer influenced strongly by beliefs about how to educate faculty. Schmid calls this as lecturer's pedagogical beliefs. One of these beliefs is the belief that technology use in learning can maximize student learning [47].

Furthermore, in addition to lecturer pedagogical beliefs towards the use of technology to maximize student learning, the other factor is about how to utilize technology in learning, so that learning delivered effectively in a well-designed learning activity.

After preparing for teaching in a series of learning activities that are designed according to pedagogic beliefs towards learning, the next is how to take advantage of the students with their computer literate to technological features. The better the students' understanding of the use of technology in support of learning, the more he get the maximum learning.

In order the learning activity that utilizes technology to be effective, it is believed that, in advance, there should be a compromise between students and lecturer regarding what technology, when and the extent to which the technology will be used in the activity. It determines how the student can be engaged in the learning. 
Overall, the use of technology as an enabler in learning needs to pay attention to these four important aspects, namely:

1) Lecturer's pedagogical beliefs

According to Pajares in Ertmer [47], this related to beliefs about teaching and learning. In the side of creative learning, this will increase the students' understanding of the course, and student engagement in learning activities.

2) Designed pedagogical activities

This relates to the use of technology in learning activities. In the creative side of learning, this determines what kind of technology used in learning, and enhances the creativity of new ideas will be formed.

3) Students' own understanding of potentials use of the technology

This relates to the ability of the students in using technology for learning. In the side of this creative learning improves student engagement and interaction among peers and with lecturer.

4) The compromises between students and the teacher about the pedagogical exploitation of technology

This relates to the time and technology used in learning. In the creative side of learning, this increases student engagement with learning.

From the perspective of group collaboration, lessons learned from the application of a placebased virtual collaboration environment conducted by Maybury [49] in 2001 reveals some critical success factors to be success on applying a collaborative virtual workspace (CVW). One of the most lessons learned is about the organizational resistance for sharing and collaboration. Despite a common goal or purpose has been determined if there is a resistance or absence of trust between members it will discourage the success of collaborative work. Therefore, in CLC technology used as a tool for learning activities need to be determined wisely between members and facilitator so that everyone in the group will participate effectively by considering some important aspects discussed in this subchapter.

\section{CONCLUSION}

The research in this thesis has been successfully modelled Technology-Enabled Creative Learning Community (T-E CLC) in Graduate School of Telkom University, Tel-U based on Information System Research Framework by Hevner et al. The resulted artifacts include constructs, conceptual model, and method to apply T-E CLC. The T-E CLC constructs consisted of two main components, namely the elements of T-E CLC and the development phase of T-E CLC in a learning environment. The conceptual model of T-E CLC was a picture of the relationship between T-E CLC constructs. Method to apply T-E CLC functioned as a guide to apply T-E CLC in a learning environment.

\section{ACKNOWLEDGMENT}

The authors would like to thank to Allah subhanatu wa ta'ala, the Almighty God, for His guidance and tawfeeq so that the authors can benefit the potentials He gave. Thanks go to the Dean and Vice Dean of School of Computing, Telkom University who facilitate the authors in publishing this paper.

\section{REFERENCES}

[1] O. T. Lenning and L. H. Ebbers, The Powerful Potential of Learning Communities: Improving Education for the Future, Washington DC: ASHE-ERIC Higher Education Report Vo. 26 No. 6, 1999.

[2] L. M. Rocconi, "The Impact of Learning Communities on First Year Students' Growth and 
Development in College," in Association for Institutional Research Conference, Chicago, 2010.

[3] C. M. Zhao and G. D. Kuh, "ADDING VALUE:Learning Communities and Student Engagement," in Research in Higher Education, Vol. 45, No. 2, California, 2004.

[4] R. Conejo, R. A., B. Barros and J. Vassileva, "Towards a group model for Learning Communities. First steps with the Comtella-D Collaborative Learning Community," in Eighth IEEE International Conference on Advanced Learning Technologies, Santander, Cantabria, 2008.

[5] M. Dooly, "Constructing Knowledge Together," in Telecollaborative Language Learning. A Guidebook to Moderating Intercultural Collaboration Online, Bern, Peter Lang, 2008, pp. 21-45.

[6] K. Nahrstedt, L. Angrave, M. Caccamo, R. Campbell, B. Godfrey, I. Gupta, K. Karahalios, R. Kravets, S. Kamin, S. Poole and W. Sanders, "Mobile Learning Communities - Are We There Yet?," Technical Report, Information Trust Institute, University of Illinois at Urbana-Champaign, November 2010, Illinois, 2010.

[7] C.-H. Leung and Y.-Y. Chan, "Mobile Learning: A New Paradigm in Electronic Learning," in The 3rd IEEE International Conference on Advanced Learning Technologies (ICALT'03), 2003.

[8] M. Milrad, "Mobile Learning: Challenges, Perspectives and Reality," 2003, pp. 151-164.

[9] Q. Li, R. W. H. Lau, T. K. Shih and F. W. B. Li, "Technology Supports for Distributed and Collaborative Learning over the Internet," in ACM Transaction on Internet Technology Vol. 8, No. 2, Article 10, 2008.

[10] I. Lee, "Ubiquitous Computing for Mobile Learning," in Asia-Pacific Cybereducation Journal, 2006.

[11] S. Martin, G. Diaz, I. Plaza, E. Ruiz, M. Castro and J. Peire, "State of the art of frameworks and middleware for Facilitating mobile and ubiquitous learning development," The Journal of Systems and Software 84, p. 1883-1891, 2011.

[12] T. G. Tucker and W. W. Winchester, Mobile Learning for Just-In-Time Applications, Clemson: ACM, 2009.

[13] J. Conesa, S. Caballé, D. Gañan and J. Prieto, "Towards the Representation of Emotional Information from On-line Collaborative Learning Sessions," in 2012 Sixth International Conference on Complex, Intelligent, and Software Intensive Systems, Palermo, 2012.

[14] M.-S. Kuo and C.-S. Lin, "Virtual Parabola Festival: The Platform Design and Learning Strategies for Virtual Learning Community of Practice," in 2010 IEEE International Conference on Digital Game and Intelligent Toy Enhanced Learning, 2010.

[15] C.-h. Hu and M. Zhao, "Construction of Collaborative Virtual Learning Communities in Peer-to-peer Networks," in Intelligent Information Hiding and Multimedia Signal Processing, 2007. IIHMSP 2007. Third International Conference on, Kaohsiung, 2007.

[16] R. Bailey, M. Shoffner and H. Rowan-Kenyon, "Special Session - Integrating Learning Communities into Engineering Curricula," in 40th ASEE/IEEE Frontiers in Education Conference, Washington, 2010.

[17] S. Feger, E. Arruda, R. Pringle and D. Briggs, "Professional Learning Communities: Key Themes from the Literature," Brown University, Rhode Island, 2008.

[18] E. R. Rentfro, "Professional Learning Communities Impact Student Success," National Association of Elementary School Principals: NAESP, Virginia, 2007.

[19] B. Soehendro, E. Indrajit, I. Sailah, I. B. Prasojo, M. Munir, M. Nurdin, Nizam, R. R. T., R. Z. Tamin and S. Manuwoto, "Panduan Penyelenggaraan Program Community College (Perguruan Tinggi Komunitas) PHP-PTS Tahun Anggaran 2011," DIREKTORAT 
PEMBELAJARAN DAN KEMAHASISWAAN DIREKTORAT JENDERAL PENDIDIKAN TINGGI KEMENTERIAN PENDIDIKAN NASIONAL, Jakarata, 2011.

[20] C. Zhou, Group Creativity Development in Engineering Education in Problem and ProjectBased Learning (PBL) Environment, Aalborg: Faculty of Engineering and Science, Aalborg University, Denmark, 2012.

[21] C. Charyton, R. J. Jagacinski and J. A. Merill, "CEDA: A research instrument for creative engineering design assessment," Psychology of Aesthetics, Creativity, and the Arts, pp. 147-154, 2008.

[22] C. Charyton and J. A. Merrill, "Assessing General Creativity and Creative Engineering Design in First Year Engineering Students," Journal of Engineering Education, pp. 145156, April 2009.

[23] S. G. Isaksen, K. J. Lauer and G. Ekvall, "Situational Outlook Quesionnaire: A Measure of the Climate for Creativity and Change," Psychological Reports, Bufallo, 1999.

[24] H. Bacanl1, M. A. Dombayc1, M. Demir and S. Tarhan, "Quadruple Thinking: Creative Thinking," in Procedia Social and Behavioral Sciences 12, Amsterdam, 2011.

[25] W. Zheng and J. Yin, "ENHANCING STUDENTS' HIGHER-ORDER SKILLS THROUGH COMMUNITY SERVICE LEARNING USING SCAFFOLDING FOR CREATIVE PROBLEM SOLVING," American Society for Engineering Education, 2012.

[26] E. d. Bono, Lateral Thinking, West Sussex: Penguin Group, 1970.

[27] P. Resta and T. Laferriere, Technology in Support of Collaborative Learning, Springer Science + Business Media, 2007.

[28] B. L. Smith and J. T. MacGregor, "What is Collaborative Learning?," Washington Center for Improving the Quality of Undergraduate Education, Washington, 2001.

[29] J. Cugini, L. Damianos, L. Hirschman, R. Kozierok, J. Kurtz, S. Laskowski and J. Scholtz, "Methodology for Evaluation of Collaboration Systems," National Institute of Standards and Technology, Maryland, 1997.

[30] L. M. POPA, "Framework for Collaborative Systems Assessment Based on Metrics," Journal of Applied Collaborative Systems, vol. 2, no. 2, pp. 18-28, 2010.

[31] S. Petter, W. DeLone and E. McLean, "Measuring information systems success: models, dimensions, measures, and interrelationships," European Journal of Information System, vol. 17, pp. 236-263, 2008.

[32] A. R. Hevner, S. T. March, J. Park and S. Ram, "Design Science in Information Systems Research," MIS Quarterly, pp. 75-105, 2004.

[33] D. D. J. Suwawi, W. Maharani and H. S. Sastramihardja, "T-E CLC: A conceptual model towards creative learning community," in 2014 International Conference of Advanced Informatics: Concept, Theory and Application (ICAICTA), Bandung, 2014.

[34] S. Adhy, Pemodelan Konseptual Budaya Belajar Berorientasi pada Kualitas Informasi Mengadaptasi Information Evolution Model untuk Meningkatkan Kinerja Organisasi Studi Kasus: PT. POS dan Bappeda Kota Bandung, Bandung: Institut Teknologi Bandung, 2012.

[35] M. Kraska, "Retention of Graduate Students Through Learning Communities," Journal of Industrial Teacher Education, vol. 45, no. 2, pp. 54-70, 5 June 2008.

[36] R.-M. Conrad and J. A. Donaldson, Engaging the Online Learner: Activities and Resources for Creative Instruction, Updated Edition ed., California: Jussey-Bass, 2011.

[37] D. D. J. Suwawi, W. Maharani and H. S. Sastramihardja, "T-E CLC: A conceptual model towards creative learning community," in 2014 International Conference of Advanced Informatics: Concept, Theory and Application (ICAICTA), Bandung, 2014.

[38] D. V. Price, "Learning Communities and Student Success in Postsecondary Education," MDRC, New York, 2005. 
[39] R. Bolam, A. McMahon, L. Stoll, S. Thomas and M. Wallace, "Creating and Sustaining Effective Professional Learning Communities," University of Bristol, Bristol, 2005.

[40] D. Lamb, S. Kabes and J. Engstrom, "Sustainable Transformation of Educators in a Graduate Learning Community Model," International Journal for Cross-Disciplinary Subjects in Education (IJCDSE), Volume 2, Issue 4, December 2011, pp. 510-517, 2011.

[41] M. D. Cox, "Introduction to Faculty Learning Communities," NEW DIRECTIONS FOR TEACHING AND LEARNING, pp. 5-23, 20 April 2004.

[42] K. Taylor, W. S. Moore, J. MacGregor and J. Lindblad, "Learning Community Research and Assessment: What We Know Now - National Learning Communities Project monograph series," Washington Center at The Evergreen State College - The National Resource Center for Learning Communities, Washington, 2003.

[43] A. M. Mastergeorge, I. Roberson, F. Martinez, L. Evans and A. Johnson, "An Evaluation of Creative Learning Communities in Classrooms: A Two-Year Study of the Implementation of School Reform," Center for the Study of Evaluation National Center for Research on Evaluation, Standards, and Student Testing Graduate School of Education \& Information Studies University of California, Los Angeles, California, 2003.

[44] S. Beal, S. Ciaperoni, B. Ilijic, L. Ktapa, M. Markowicz, M. Miktosz, D. Olivier, M. Refalo and J. Woods, "CLC Manual," Lifelong Learning Programme, Leonardo da Vinci 2011 2013, Development of Innovation, 0509 2013. [Online]. Available: http://www.skills4me.eu/downloads/man/MAN_EN.pdf. [Accessed 20 November 2013].

[45] S. G. Isaksen and S. J. Parnes, "Curriculum Planning for Creative Thinking and Problem Solving," Journal of Creative Behavior, vol. 19, no. 1, pp. 1-29, 1985.

[46] S. A. IANNARINO, "Initiative: The Ability to Take Action Proactively," 01 January 2010. [Online]. Available: http://thesalesblog.com/blog/2010/01/30/initiative-the-ability-to-takeaction-proactively/. [Accessed 02 December 2013].

[47] N. Z. Amarin and R. I. Ghishan, "Learning With Technology from a Constructivist Point of View," International Journal of Business, Humanities and Technology, vol. 3, no. 1, pp. 52-57, 2013.

[48] P. A. Ertmer, "Teacher Pedagogical Beliefs and Classroom Technology Use: A Critical Link," Purdue University, Indiana, 2006.

[49] M. T. Maybury, "Expert Finding for Collaborative Virtual Environments," Communications of the ACM, vol. 44, no. 12, pp. 51-54, 2001. 